\title{
IMPLEMENTAÇÃO DE FERRAMENTAS DA QUALIDADE PARA GESTÃO DE ESTOQUE EM UMA LOJA DE CONVENIÊNCIA
}

\author{
APPLICATION OF QUALITY TOOLS FOR INVENTORY MANAGEMENT IN A CONVENIENCE STORE
}

\section{Rafael da Penha Tavares Gomes Nunes ${ }^{1}$, Marcos Wagner Jesus Servare Junior ${ }^{2^{*}}, \boldsymbol{\&}$ Thiara Cezana Gomes ${ }^{3}$ \\ ${ }^{12}$ Centro Universitário Salesiano - Unisales ${ }^{3}$ Universidade Federal do Espírito Santo - UFES \\ ${ }^{1}$ rafael.tavares17@ hotmail.com ${ }^{2 *}$ marcoswjunior@gmail.com ${ }^{3}$ thiaracezana@gmail.com}

\section{ARTIGO INFO.}

\section{Recebido em: 12.12.2021}

Aprovado em: 02.02.2022

Disponibilizado em: 08.02.2022

\section{Palavras-chave:}

Controle de Estoque; Ferramentas da Qualidade; Lojas de Conveniência.

\section{KEYWORDS:}

Inventory control; Quality tools; Convenience stores.

*Autor Correspondente: Servare, M. W. J., Jr.

\section{RESUMO}

Controlar o estoque de forma adequada é uma das formas de obter sucesso em qualquer ramo de atividade, contudo, é possível perceber que muitas empresas ainda são insuficientes nessa área, trazendo um impacto negativo no seu fluxo de caixa e materiais. Sabe-se que o mercado de micros e pequenas empresas é responsável por movimentar grande parte da economia do país, e por essa razão, o estudo justifica-se pela necessidade de enfatizar processos que por muitas vezes parecem ser irrelevantes neste mercado, como o controle do fluxo logístico em uma loja de conveniência. A empresa escolhida é uma empresa do ramo de comércio varejista de mercadorias localizada no estado do Espírito Santo, no município de Vila Velha. Com aproximadamente 2 anos de mercado, a loja de conveniência trabalha com venda e salgados, bebidas, cigarros e outros produtos. Nesse sentido, utilizando ferramentas de controle e gestão, é possível melhorar o processo de entrada e saída de mercadorias da loja de conveniência retratada, bem como o fluxo financeiro e previsão de demanda. Para alcançar o objetivo deste trabalho, foram utilizadas as ferramentas Curva ABC, Diagrama de Ishikawa, 5S e 5W2H.

\begin{abstract}
Properly controlling inventory is one of the ways to be successful in any field of activity, however, it is possible to see that many companies are still insufficient in this area, bringing a negative impact on their cash flow and materials, generating non-specific waste. It is known that the micro and small business market is responsible for moving a large part of the country's economy, and for this reason, the study is justified by the need to emphasize processes that often seem to be irrelevant in this market, such as control of the logistical flow in a convenience store. The chosen company is a company in the retail merchandise trade sector located in the state of Espírito Santo, in the municipality of Vila Velha. With approximately 2 years in the market, the convenience store sells snacks, beverages, cigarettes and other products. In this sense, using control and management tools, it is possible to improve the process of entry and exit of goods at the convenience store portrayed, as well as the financial flow and demand forecast. To achieve the objective of this work, it is necessary to use tools $A B C$ curve, Ishikawa diagram, $5 \mathrm{~S}$ and $5 \mathrm{~W} 2 \mathrm{H}$.
\end{abstract}



de estoque em uma loja de conveniência. Brazilian Journal of Production Engineering, 8(2), 62-78.

\section{INTRODUÇÃO}

No atual cenário globalizado, com o rápido crescimento das redes de comércio varejista de mercadorias, como as lojas de conveniência, buscar ser competitivo tornou-se um fator crucial. Segundo o Sindicato Nacional das Empresas Distribuidoras de Combustíveis e de Lubrificantes (Sindicom, 2018), através das lojas de conveniência, registrou-se em 2016 uma expansão de 6,2\% e um faturamento de $\mathrm{R} \$ 7,2$ bilhões. Para isso, enxergar as necessidades de um mercado cada vez mais exigente e buscar métodos que as tornem competitivas faz com que o negócio seja mais atraente e vantajoso.

Nesse sentido, saber controlar o estoque de forma adequada é uma das formas de obter sucesso. Contudo, percebe-se que muitas redes de varejo ainda são insuficientes nessa área, trazendo um impacto negativo no seu fluxo de caixa e materiais, gerando desperdícios não pontuais. Para este problema, pode-se afirmar que algumas das possíveis causas das ocorrências acontecem devido à falta de conhecimento de gestão dos proprietários; falta de controle dos processos logísticos e do fluxo financeiro; e a falha na identificação do público-alvo. Segundo Freitas (2008), a gestão de estoque é uma das atividades chave para a administração da empresa, pois ela está relacionada com a eficiência das empresas em gerirem seus processos. Portanto, entender e controlar o estoque é fundamental para que uma empresa, independente do seu porte, possa alavancar e crescer com seu negócio.

De acordo com Slack, Chambers e Johnston (2009), o principal objetivo do estoque é cobrir as eventualidades que podem ocorrer na demanda ou no fornecimento. Para Fernandes e Godinho Filho (2010), os estoques divididos em três tipos, sendo eles: estoques de insumos, onde os componentes são matéria-prima, embalagem e material de suprimentos; estoques em processamento, com os produtos semiacabados e produtos em processo; e por fim, estoques de itens finais, com os produtos acabados e sobressalentes.

Slack, Chambers e Johnston (2009) aponta que existem fatores negativos com relação aos estoques, sendo alguns deles: congelamento do capital, o que compromete o capital de giro e até o fluxo de caixa; e custos adicionais, para manter os insumos em perfeito estado de conservação, e para alguns casos, o material pode-se tornar obsoleto e/ou deteriorar. Como mencionado, o estoque pode acabar se tornando um perigo, por consumir espaço e comprometer o capital da organização.

Com base nos relatos anteriores, é possível perceber a necessidade da aplicação de métodos para controlar os estoques de forma eficiente, com o intuito de reduzir tais pontos negativos que decorrem muita das vezes pela falta de entendimento no assunto abordado.

Sabe-se que o mercado de micros e pequenas empresas é responsável por movimentar grande parte da economia do país, e por essa razão o estudo justifica-se pela necessidade de enfatizar processos que por muitas vezes parecem ser irrelevantes neste mercado, como o controle do fluxo logístico em uma loja de conveniência (Guerra \& Teixeira, 2010). Nesse sentido, utilizando ferramentas de controle e gestão, é possível melhorar o processo de entrada e saída de mercadorias da loja de conveniência retratada, bem como o fluxo financeiro e previsão de demanda. 
O objetivo deste artigo é compreender o processo de entrada e saída de mercadorias de uma loja de conveniência, para assim, elaborar um plano estratégico a fim de otimizar tal procedimento e melhorar o fluxo logístico e financeiro a partir da utilização de ferramentas como curva $\mathrm{ABC}$, diagrama de Ishikawa, $5 \mathrm{~S}$ e $5 \mathrm{~W} 2 \mathrm{H}$.

O artigo apresenta a seguinte estrutura: na primeira seção, a introdução; na segunda seção, a revisão da literatura contemplando estudos englobados pela pesquisa; na terceira seção, uma breve abordagem sobre a empresa estudada, definição do problema e levantamento de dados; na quarta seção, apresenta-se a parte prática do trabalho e a análise dos resultados obtidos por meio da aplicação das ferramentas; por fim, na quinta seção, as considerações finais e propostas de estudos futuros.

\section{REFERENCIAL TEÓRICO}

\subsection{Ferramentas da Qualidade}

\subsubsection{Diagrama de Ishikawa}

O digrama de Ishikawa é uma das sete ferramentas da qualidade, sendo usado para encontrar, organizar, classificar, documentar e exibir graficamente as causas de um determinado problema, agrupados por categorias, que facilitam o brainstorming e a análise da ocorrência. Também é conhecido como diagrama de Espinha de Peixe, pelo seu formato, ou diagrama de Causa e Efeito, por ser composto por um conjunto de causas e por um efeito (produto, resultado ou problema) (Werkema, 1995; Campos, 2004; Carvalho \& Paladini, 2013).

As causas são categorizadas em seis grupos, conhecidos como 6 M: (i) Máquina; (ii) Material; (iii) Mão de obra; (iv) Meio ambiente; (v) Método; (vi) Medida (Lins, 1993), detalhados a seguir.

- Máquina: diversos problemas provêm de falhas em máquinas e equipamentos. Portanto, é importante analisar o funcionamento dos equipamentos para evitar gastos desnecessárias;

- Material: tem por objetivo analisar situações em que existam materiais fora das especificações e/ou em quantidade incorreta;

- Mão de Obra: relacionada com as atitudes dos colaboradores na execução das atividades;

- Meio Ambiente: formado pelos problemas que estão relacionados aos ambientes internos e externos da organização;

- Método: incorporar no dia a dia os padrões e procedimentos definidos se comprometendo em manter os sensos na rotina de trabalho;

- Medida: refere-se aos procedimentos adotados durante as atividades, podendo conter a utilização de softwares e ferramentas de planejamento.

\subsubsection{S}

A ferramenta 5S foi desenvolvida no Japão, após a Segunda Guerra Mundial, por volta de 1950, com o objetivo de auxiliar as empresas se reerguerem, eliminando o desperdício, esforços excessivos, problemas com higiene, limpeza e produtividade baixa (Rebello, 2005; Trainotti, 2007). A nomenclatura 5S remete aos cinco sensos, que no meio organizacional tem o sentido de ser uma capacidade de discernir e manter a atenção em pontos na organização (Ishikawa, 1986). Nesse sentido, o 5S aborda os seguintes sensos:

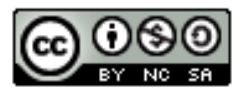



de estoque em uma loja de conveniência. Brazilian Journal of Production Engineering, 8(2), 62-78.

- Seiri, senso de Utilização: o foco é eliminar o que não é útil, separando o necessário do desnecessário e descartando o que for supérfluo;

- Seiton, senso de Organização: organizar o ambiente de trabalho, arrumando as coisas nos seus lugares adequados para uso;

- Seiso, senso de Limpeza: limpeza e higiene do ambiente de trabalho;

- Seikitsu, senso de Padronização: estabelecer e desenvolver padrões e procedimentos a serem seguidos, em relação ao definido nos $3 \mathrm{~S}$ anteriores;

- Shitsuke, senso de Disciplina: incorporar na rotina os padrões e procedimentos definidos, comprometendo-se em manter os sensos na rotina de trabalho.

Segundo Silva et al. (2016), a implantação da ferramenta proporciona diversas vantagens como redução de custos, pois os recursos são mais bem aproveitados; melhor gerenciamento de tempo e do espaço físico utilizado pelos colaboradores; clima organizacional agradável e maior motivação dos colaboradores; melhoria dos processos de comunicação; redução da probabilidade de ocorrências de acidentes, tornando o local mais seguro; melhoria na qualidade de produtos e serviços, visto que um ambiente limpo e organizado induz à inovação, incentivando práticas de melhoria, além de estimular entregas de qualidade e a realização de um trabalho bem feito.

Para implementação eficiente do programa 5S, torna-se necessário uma mudança cultural e comportamental de toda a organização (Silva, 1996). Na prática, é possível afirmar que sua implantação é categorizada em duas partes. Na primeira etapa, os três primeiros sensos são aplicados na seguinte sequência: Seiri (senso de Utilização), aplicado na eliminação do que é desnecessário no ambiente de trabalho; Seiton (senso de Organização), com foco em deixar as coisas nos seus devidos lugares; e, por fim, Seiso (senso de Limpeza), mantendo o ambiente limpo e higienizado.

Após implantação dos três primeiros sensos, a segunda parte deve ser iniciada. Com isso, restam apenas os dois últimos sensos, que devem ser aplicados na seguinte ordem: Seikitsu (senso de Padronização), padronizando e documentando o que foi feito nos 3Ss da etapa anterior; e por fim, a implantação do Shitsuke (senso de Disciplina), com o intuito de fazer com que o processo continue, através da disciplina de toda organização.

\subsubsection{Curva ABC}

A curva $\mathrm{ABC}$ é baseada na teoria de Pareto, na qual são divididos os estoques em classes A, B e C. Trata-se de uma ferramenta que facilita a tomada de decisão, uma vez que auxilia na análise e processamento das informações, com o intuito de classificar os recursos conforme sua quantidade e importância. Essa metodologia estabelece uma ordem de prioridade, visando separar os itens, priorizando os que agregam mais valor para a empresa. Sua aplicação e uso ajudam a definir a estratégia de quais itens em estoque poderão ter prioridades (Santos \& Lubiana, 2017).

Segundo Arnold (1999), a Classe A representa os itens de maior prioridade ou importância, que precisam de maior atenção pelo seu valor. É estimado que $20 \%$ dos itens correspondam a $80 \%$ do valor do estoque; a Classe B inclui itens com importância, quantidade ou valor intermediário. Representam cerca de $15 \%$ do valor distribuído em $30 \%$ dos itens; e a Classe C, refere-se aos itens classificados como baixa prioridade, onde seu impacto econômico na companhia é menor que os anteriores. Os itens dessa categoria representam, em média, 5\% do valor monetário em

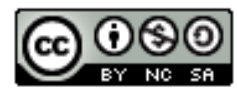


Citação (APA): Nunes, R. P. T. G., Servare, M. W. J., Jr., \& Gomes, T. C. (2022). Implementação de ferramentas da qualidade para gestão de estoque em uma loja de conveniência. Brazilian Journal of Production Engineering, 8(2), 62-78.

$50 \%$ da mercadoria. É importante ressaltar que esses valores percentuais das divisões das classes $\mathrm{ABC}$ são orientativos e não devem ser tomados como regra geral.

Esse método é comumente utilizado para um controle mais apurado de produtos em um gerenciamento de estoque (Santos \& Lubiana, 2017). De compreensão simples, a curva ABC resulta em um gráfico que auxilia na análise dos itens em estoque, no nível de lucratividade e no grau de representação do faturamento da organização.

\subsubsection{W2H}

A ferramenta $5 \mathrm{~W} 2 \mathrm{H}$ consiste em um plano de ação para atividades pré-estabelecidas com intuito de compreender um determinado problema e propor soluções e/ou melhorias para eliminar o mesmo (Polacinski et al., 2013). Para isso, deve-se responder a sete questões, sendo elas: What? (O quê?), Why? (Por quê?), When? (Quando?), Where? (Onde?), Who? (Por quem?), How? (Como?), How much? (Quanto?). A seguir o detalhamento de cada categoria.

- What (O quê?): descrever o problema, relatando o objetivo ou a melhoria proposta;

- Why (Por quê?): declarar a importância e o motivo para resolução do problema;

- When (Quando?): definir os prazos para concluir cada melhoria proposta;

- Where (Onde?): comentar o local de aplicação da melhoria, podendo ser um setor ou até mesmo uma máquina;

- Who (Quem?): definir responsável ou equipe designada para implementar a melhoria sugerida;

- How (Como?): conhecendo as etapas e suas falhas é possível determinar como as melhorias serão aplicadas, para assim, solucionar os problemas encontrados;

- How much (Quanto?): para essa etapa são mencionadas informações de custo e/ou quantidade, mas existem casos em que os gastos não existem.

Dessa maneira, a aplicação da ferramenta identifica, segmenta e estrutura de forma sistematizada as ações de um projeto (Gomes et al., 2018).

\subsection{Aplicações de Ferramentas da Qualidade na Gestão de Estoques}

Para Cabral, Zeitouni e Souza (2017), as ferramentas da qualidade podem ser usadas como método para resolução de problemas. Sua contribuição é de extrema importância para análise, detecção e solução de problemas na distribuição de produtos.

Neste sentido, Possale e Callefi (2020) utilizaram o ciclo PDCA com o intuito de reduzir o número de não conformidades e aumentar a produtividade em setores específicos de uma empresa do setor metal mecânico. Dentre as ferramentas da qualidade aplicadas, listam-se gráfico de Pareto, diagrama de Ishikawa, 5S e 5W2H. Por meio da implementação do programa 5S no setor de almoxarifado notou-se melhora da organização do local, ocasionando maior velocidade no atendimento às requisições internas de materiais e melhor gestão de estoque.

Lucas et al. (2018) também defendem a sistematização do controle de estoque com auxílio de ferramentas da qualidade. No estudo de caso realizado em uma empresa de beneficiamento de sementes, o diagrama de Ishikawa e o programa $5 \mathrm{~S}$ mostraram-se úteis na detecção de falhas no controle dos estoques e, por consequência, na tomada de decisão.

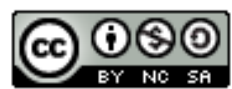

Esta obra está licenciada com uma Licença Creative Commons Atribuição-Não Comercial-Compartilha Igual 4.0 Internacional. Brazilian Journal of Production Engineering, São Mateus, Editora UFES/CEUNES/DETEC. 
Reis et al. (2019) adotaram a Metodologia de Análise e Solução de Problemas (MASP) e ferramentas da qualidade para melhoria dos processos de controle de estoque. A aplicação do método auxiliou na detecção das causas dos problemas e na solução e alcance de melhorias no ambiente organizacional para a obtenção de resultados otimizados.

De acordo com Ajala e Giordani (2018), o uso de ferramentas como a curva ABC contribuiu para que a organização fosse capaz de rever seus conceitos de estocagem, layout, endereçamento e outros fatores que afetam de forma direta e indireta os processos de organização e controle dos estoques.

Piran, Azzolini e Vanin (2020) aplicaram ferramentas da qualidade para controle de estoque em uma empresa do setor de distribuição de alimentos. Por meio da classificação ABC foi possível identificar produtos com maior margem de contribuição. Em seguida, realizou-se o cálculo do estoque de segurança destes e também a implementação da ferramenta kanban para gerenciar e controlar o estoque e realizar a gestão à vista. Os resultados mostraram redução no índice de falta de produtos.

Por fim, uma revisão mais detalhada sobre controle de estoque como diferencial estratégico encontra-se em Giacomin, Gomes e Servare Junior (2021). Os autores, com auxílio do método ProKnow-C, analisaram o portfólio bibliográfico e notaram ampla discussão do tema em diversas regiões brasileiras e internacionais.

\section{DEFINIÇÃO DO PROBLEMA}

A empresa escolhida é uma empresa do ramo de comércio varejista de mercadorias localizada no estado do Espírito Santo, no município de Vila Velha. Com, aproximadamente, 2 anos de mercado, a loja de conveniência trabalha com venda de salgados, bebidas, cigarros e outros produtos. $\mathrm{O}$ estabelecimento é familiar e composto por três pessoas, sendo pai e filho mais velho responsáveis por toda loja, desde a parte burocrática e administrativa, como pagamento de fornecedores, organização do estabelecimento e compra/controle de materiais, até o setor operacional quando necessário, auxiliando o terceiro funcionário no caixa, limpeza do local e preparação dos salgados, por exemplo.

Para administrar de forma adequada o negócio, saber controlar o estoque é um método essencial para se obter sucesso neste ramo. É cabível ressaltar que na empresa estudada existem problemas com o controle do estoque e organização. Assim, torna-se relevante a necessidade a gestão eficaz dos recursos disponíveis para melhor controle e previsão do fluxo logístico.

\subsection{Levantamento de Dados}

Quanto à família de produtos escolhidos, o conjunto selecionado foi o dos cigarros, como já comentado anteriormente. O motivo pelo qual esse grupo foi escolhido, dar-se-á pelo fato de ser um conjunto que possui mais de 20 produtos/marcas diferentes para fazer comparação. Inicialmente, foram coletados dados dos últimos três meses do conjunto (de junho até agosto de 2021), e para isso, utilizou-se a ferramenta Microsoft Excel para armazenar as informações e tratar os dados adquiridos. No final da coleta, foi necessário fazer uma média das quantidades

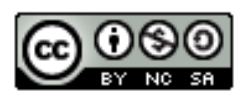


para obter um valor aproximado da demanda naquele período. Na Tabela 1 observa-se informações importantes do conjunto de produtos selecionados:

Tabela 1. Listagem da família de produtos - cigarros

\begin{tabular}{lccc}
\hline \multicolumn{1}{c}{ Produto } & Período & Unidade de medida & Quantidade \\
\hline Chesterfield Blue & Mensal & Maço & 5 \\
Chesterfield Orange & Mensal & Maço & 5 \\
Dunhill Carlton & Mensal & Maço & 224 \\
Dunhill Carlton Double Essense & Mensal & Maço & 57 \\
Dunhill Carlton Effect & Mensal & Maço & 10 \\
Kent Derby Azul & Mensal & Maço & 7 \\
Kent Derby Prata & Mensal & Maço & 5 \\
Kent Free Azul & Mensal & Maço & 4 \\
Kent Free Vermelho & Mensal & Maço & 4 \\
Lucky Strike Azul & Mensal & Maço & 20 \\
Lucky Strike Double & Mensal & Maço & 44 \\
Lucky Strike Original Azul & Mensal & Maço & 20 \\
Lucky Strike Original Vermelho & Mensal & Maço & 10 \\
Lucky Strike Verde & Mensal & Maço & 20 \\
Malboro Fusion & Mensal & Maço & 27 \\
Malboro Gold & Mensal & Maço & 5 \\
Malboro Purple & Mensal & Maço & 10 \\
Rothmans Azul & Mensal & Maço & 57 \\
Rothmans Int. Double click & Mensal & Maço & 10 \\
Rothmans Internacional & Mensal & Maço & 14 \\
Rothmans Vermelho & Mensal & Maço & 14 \\
\hline
\end{tabular}

Após tratamento dos dados coletados e armazenamento dele, foi possível criar a tabela com a média das quantidades compradas e estocadas na loja de conveniência mensalmente. As aquisições acontecem em média duas vezes por mês, facilitando o fluxo de caixa para pagamento a prazo dos produtos. É notório que a marca de cigarros Dunhill possui a maior fatia das vendas, e neste caso também dos lucros, por se uma marca bem conhecida e aceita pelo público que frequenta o estabelecimento.

Com essas informações, torna-se possível seguir com a aplicação prática deste trabalho, seguindo com o próximo método utilizado, a fim de atingir o objetivo chave deste artigo, que dar-se-á na compreensão da logística de mercadorias da loja de conveniência estudada, para então, elaborar um plano estratégico que otimize o fluxo logístico e financeiro.

\section{RESULTADOS E DISCUSSÃO}

\subsection{Diagrama De Ishikawa}

A aplicação do diagrama de causa e efeito foi importante para detectar pontos chaves de possíveis falhas que juntas compõem o problema, que é a má gestão do estoque. Para esta fase do trabalho, foram definidos quatro dos seis M, sendo eles: Método, Materiais, Mão de obra e Meio ambiente.

A Figura 1 representa o digrama de espinha de peixe estruturado com as causas levantadas neste tópico. Em seguida, serão detalhados cada $\mathrm{M}$ da ferramenta aplicada.

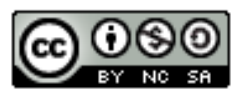


Figura 1. Diagrama de Ishikawa

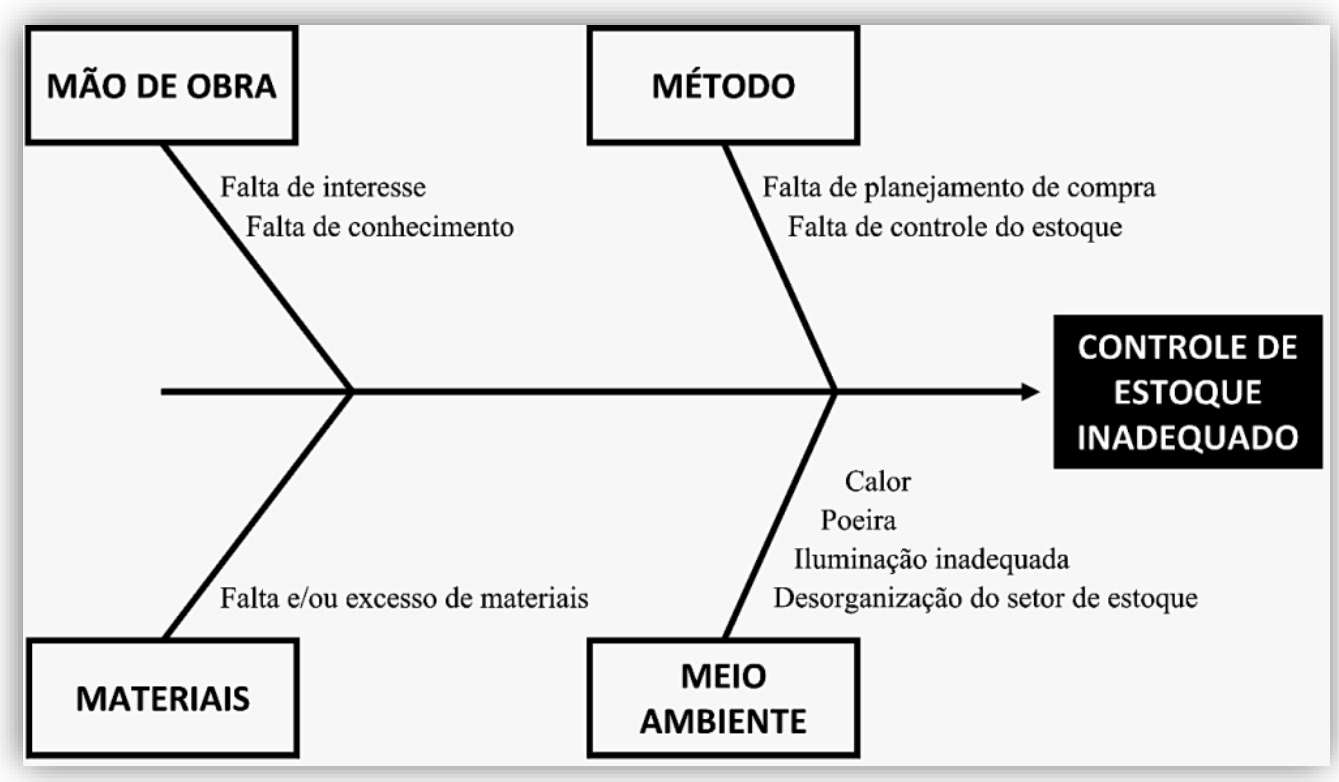

Falta de planejamento de compras e de controle do estoque estão relacionadas a categoria Método no diagrama 6M. A loja de conveniência possui um cronograma de aquisição de materiais quinzenal, entretanto, as solicitações não seguem uma análise estruturada e as compras são feitas em quantidades distintas, conforme avaliação de saída dos produtos pelos proprietários.

A classe Materiais está essencialmente ligada ao Método, pois existe uma deficiência no controle e planejamento do estoque. Assim, provavelmente, haverá problemas quanto as quantidades necessárias de cada item para atender determinado período, ocasionado falta e/ou excesso de materiais no almoxarifado.

A falta de interesse e a falta de conhecimento na gestão de estoque estruturam as causas da categoria Mão de obra. Tais causas são primordiais para que os colaboradores possam entender não apenas os conceitos da próxima ferramenta aplicada, que é o $5 \mathrm{~S}$, como também conseguir manter todas as melhorias que serão propostas ao final do desenvolvimento deste trabalho.

Para este último requisito, denominado como Meio ambiente, é possível destacar quatro causas, sendo elas: iluminação inadequada, poeira, calor e setor de estoque desorganizado. Esses pontos são de grande relevância, pois relacionam-se diretamente a questões visuais e de deslocamento dentro do almoxarifado, além de comprometerem a qualidade dos produtos estocados.

A aplicação do diagrama de Ishikawa mostra-se de extrema importância para construção e desenvolvimento das aplicações posteriores. Pois a partir de sua análise, é possível detectar causas de um problema que, por fim, serão mais bem estudadas e solucionadas com as ferramentas futuras.

\subsection{Aplicação da Ferramenta 5s}

A utilização da ferramenta $5 \mathrm{~S}$ deu-se com objetivo de melhorar a organização do setor de estoque da loja de conveniência estudada, conforme causa elencada no diagrama de Ishikawa.

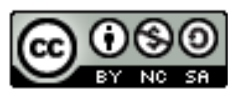



de estoque em uma loja de conveniência. Brazilian Journal of Production Engineering, 8(2), 62-78.

A aplicação do 5S visa auxiliar na melhoria da qualidade e na visualização dos cigarros disponíveis em estoque. Em um primeiro momento, para melhor monitoramento do conjunto estudado, foi definido um outro espaço para o armazenamento dos cigarros, com objetivo de deixá-los mais próximos do local de venda e do repositor, minimizando o deslocamento e maximizando o ganho de tempo. A Figura 2 retrata o antigo e novo local de estocagem dos tabacos.

Figura 2. Mudança de estoque

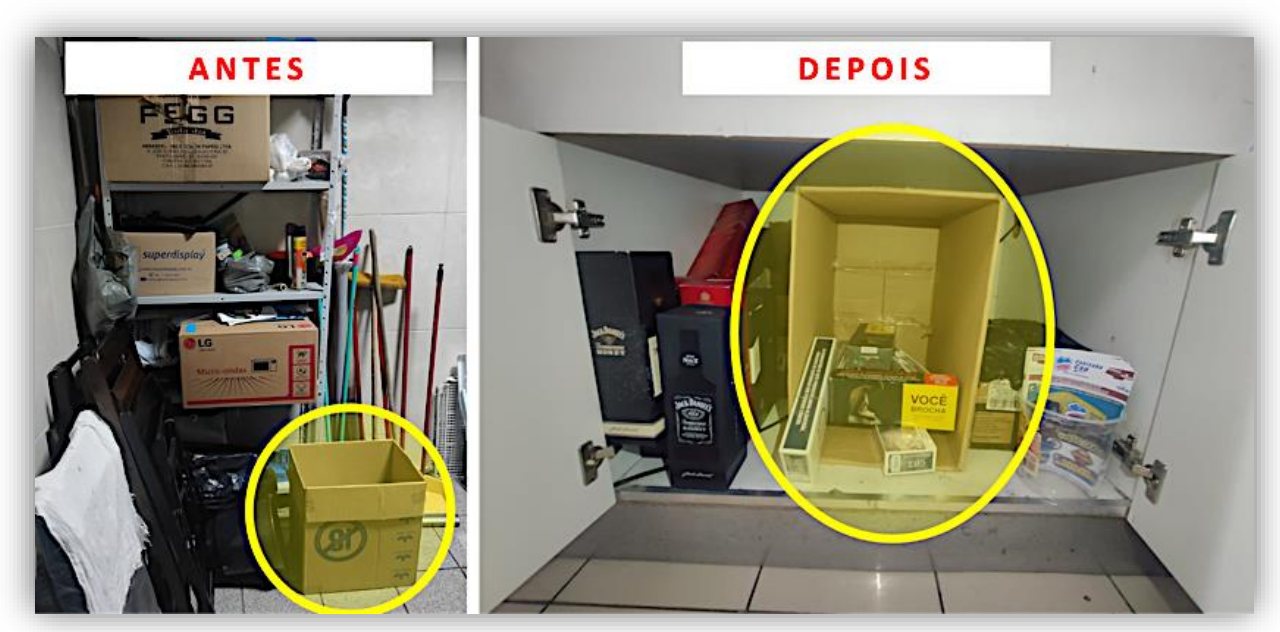

Após mudança do local de armazenamento dos cigarros, torna-se necessário seguir a metodologia em cinco fases, conforme apresentado a seguir.

Na primeira etapa, no senso de utilização, olhando apenas para o conjunto de produto estudado, o grupo dos tabacos, foi necessário destacar no estoque os itens que fazem diferença, ou seja, os itens do conjunto que possuem maior rotatividade, para assim, deixá-los em um local estrategicamente melhor e mais fácil retirada. Portanto, foi feita uma coleta de dados e análise dos itens mais relevantes no estoque, demonstrados nas próximas seções, com o intuito de melhor posicioná-los dentro do almoxarifado. A Figura 3 detalha os itens no novo local e como estão dispostos no espaço atual.

Figura 3. Organização dos cigarros e estoque de emergência
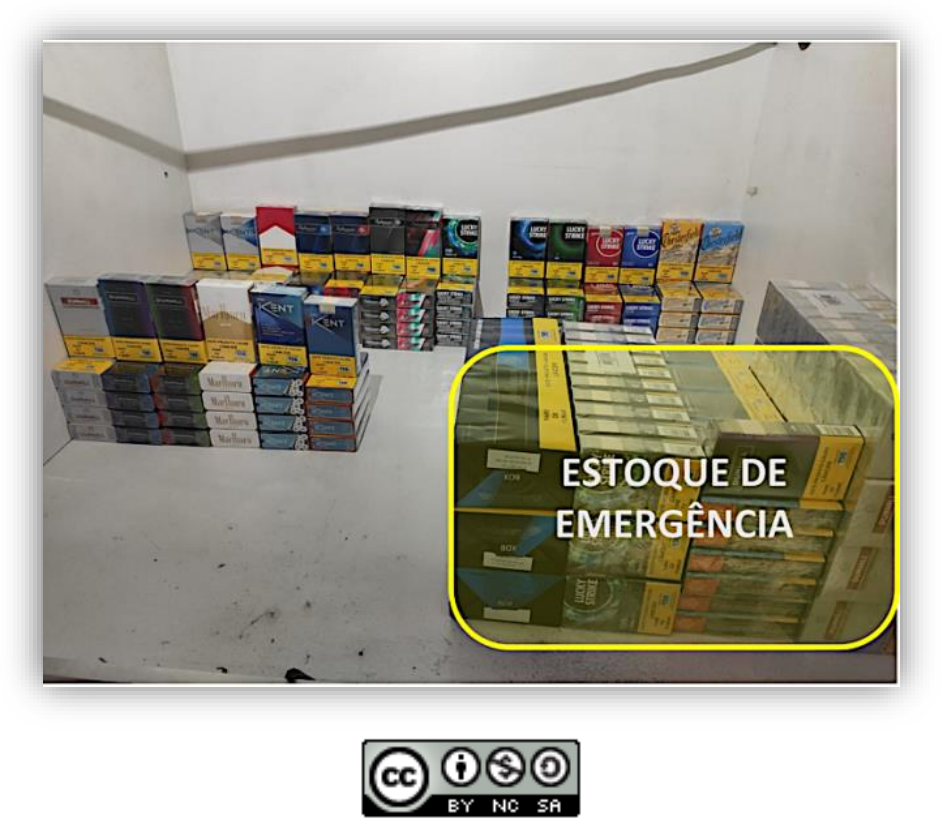

Esta obra está licenciada com uma Licença Creative Commons Atribuição-Não Comercial-Compartilha Igual 4.0 Internacional. Brazilian Journal of Production Engineering, São Mateus, Editora UFES/CEUNES/DETEC. 
Citação (APA): Nunes, R. P. T. G., Servare, M. W. J., Jr., \& Gomes, T. C. (2022). Implementação de ferramentas da qualidade para gestão de estoque em uma loja de conveniência. Brazilian Journal of Production Engineering, 8(2), 62-78.

O acondicionamento inadequado dos cigarros acabava gerando uma deficiência na visualização dos itens com baixo estoque e que necessitavam de reposição imediata. Visando melhor visualização dos itens disponíveis no estoque, foi realizado no segundo passo da metodologia, o senso de organização, que possibilitou uma disposição mais adequada para os itens, separando-os no novo local de armazenagem. É possível visualizar por meio da Figura 4 como o estoque ficou mais organizado.

Figura 4. Disposição mais adequada dos cigarros

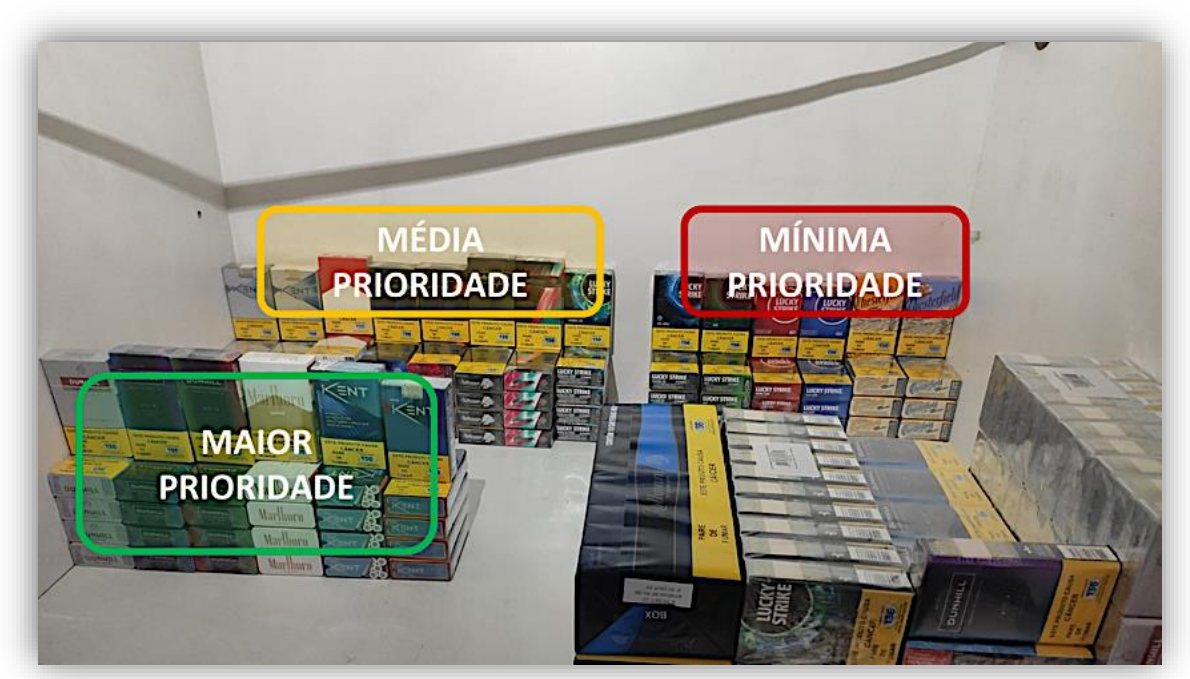

Na fase do senso de limpeza, foi possível observar que o estoque da loja estava razoavelmente desorganizado, e que possuía apenas poucos materiais desnecessários ocupando o espaço do local. Com isso, foi realizada limpeza e descarte dos itens desnecessários do ambiente, proporcionando mais espaço e ajudando na visibilidade da área, conforme Figura 5.

Figura 5. Limpeza e descarte de itens desnecessários

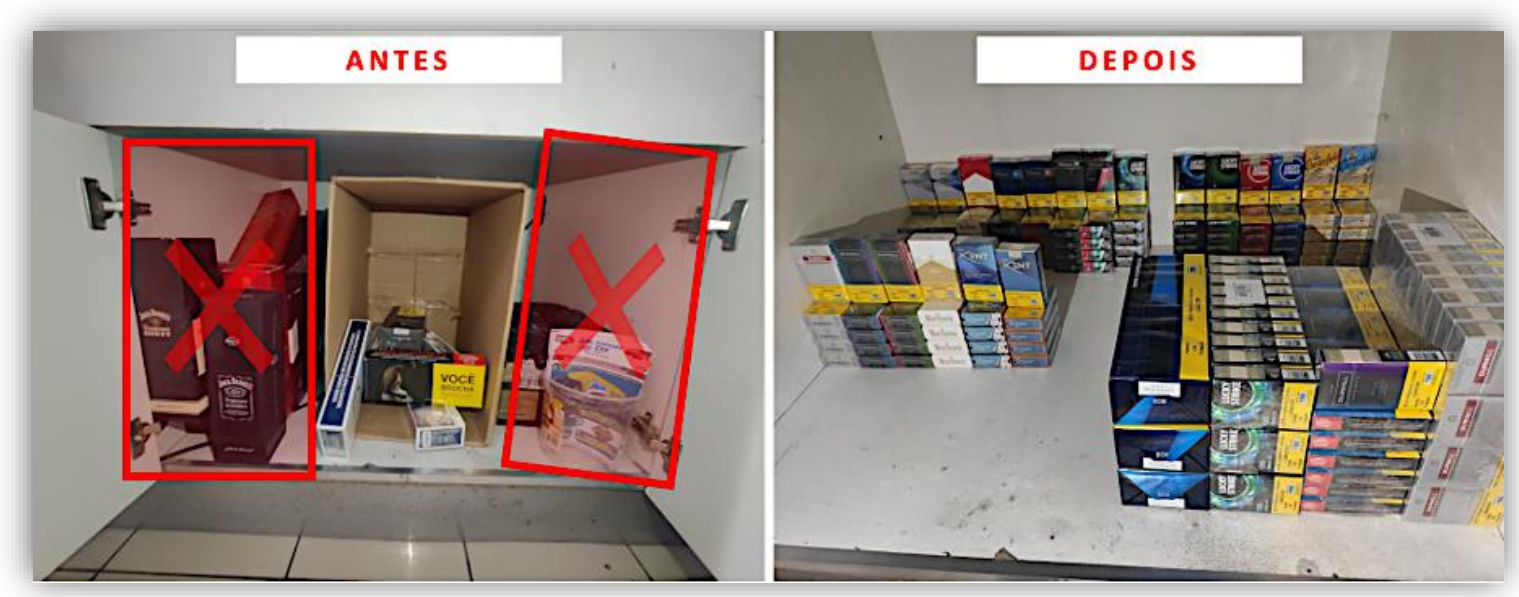

A padronização é a quarta etapa da aplicação desta ferramenta. Nela foram definidos os espaços da Figura 4 para melhor localização dos cigarros por marca e prioridade. Após aplicar esta pequena mudança, é possível observar grande melhoria na visualização do estoque, proporcionando precisão dos produtos e economizando tempo de procura por materiais.

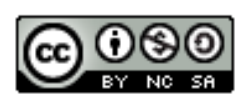


Citação (APA): Nunes, R. P. T. G., Servare, M. W. J., Jr., \& Gomes, T. C. (2022). Implementação de ferramentas da qualidade para gestão de estoque em uma loja de conveniência. Brazilian Journal of Production Engineering, 8(2), 62-78.

Por fim, o senso de disciplina visa criar meios para manter uma constância nos processos realizados anteriormente, pois de nada adiantará se os colaboradores da empresa estudada não tiverem disciplina para e manter tais mudanças diariamente. Para isso, foi realizada uma conversa com os mantenedores do estoque da loja de conveniência para darem continuidade no processo de organização e melhoria contínua. Assim, a Figura 6 mostra em detalhes toda a evolução do armazenamento dos cigarros, desde sua localização até organização e limpeza.

Figura 6. Evolução com a ferramenta $5 \mathrm{~S}$
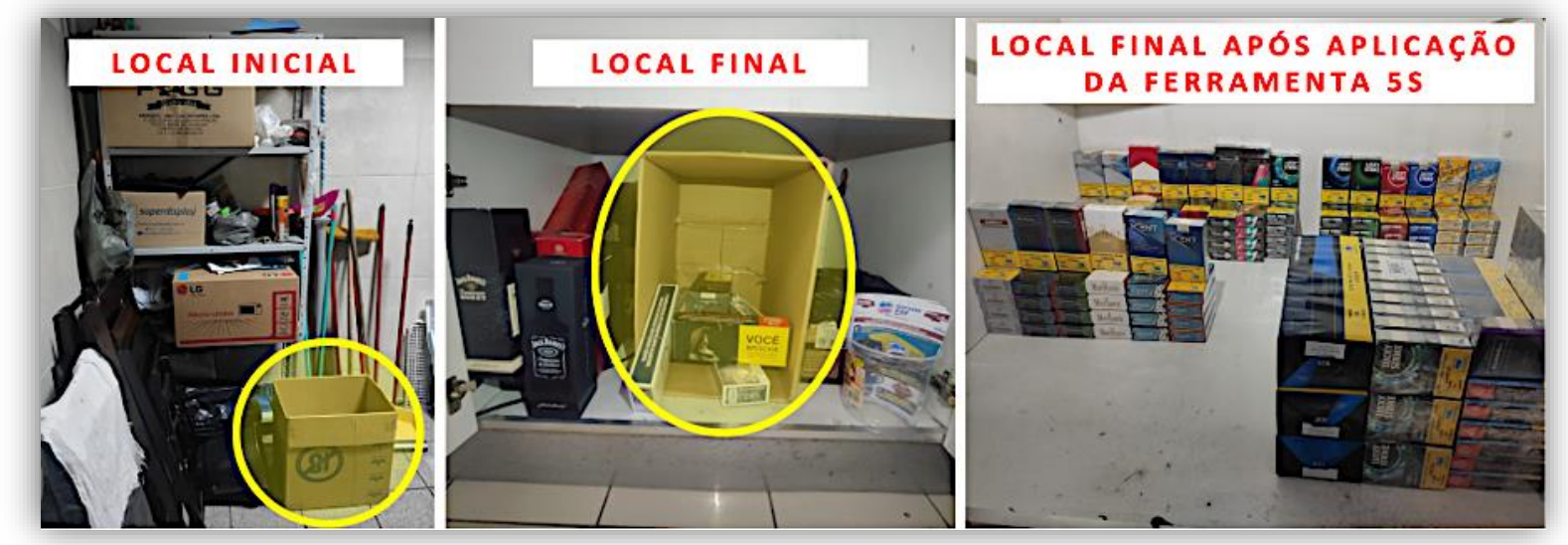

\subsection{CURVA ABC}

Para esta etapa, com a listagem dos itens do grupo selecionado, utilizou-se a curva ABC para encontrar os itens de maior representatividade e importância dentro da família de produtos dos cigarros. A primeira parte já foi realizada anteriormente e a próxima é descobrir o valor total de cada item, para assim, reorganizar a lista em forma decrescente, conforme Tabela 2.

Tabela 2. Ordenação dos itens

\begin{tabular}{clccccc}
\hline $\mathbf{N}^{\mathbf{0}}$ & \multicolumn{1}{c}{ Produto } & Período & $\begin{array}{c}\text { Unidade de } \\
\text { medida }\end{array}$ & Quantidade & $\begin{array}{c}\text { Valor } \\
\text { unitário }\end{array}$ & Valor total \\
\hline 1 & Dunhill Carlton & Mensal & Maço & 224 & $\mathrm{R} \$ 9,40$ & $\mathrm{R} \$ 2.105,60$ \\
2 & Dunhill Carlton Double Essense & Mensal & Maço & 57 & $\mathrm{R} \$ 9,86$ & $\mathrm{R} \$ 562,02$ \\
3 & Lucky Strike Double & Mensal & Maço & 44 & $\mathrm{R} \$ 8,03$ & $\mathrm{R} \$ 353,32$ \\
4 & Rothmans Azul & Mensal & Maço & 57 & $\mathrm{R} \$ 5,28$ & $\mathrm{R} \$ 300,85$ \\
5 & Malboro Fusion & Mensal & Maço & 27 & $\mathrm{R} \$ 9,21$ & $\mathrm{R} \$ 248,67$ \\
6 & Lucky Strike Azul & Mensal & Maço & 20 & $\mathrm{R} \$ 7,80$ & $\mathrm{R} \$ 156,00$ \\
7 & Lucky Strike Verde & Mensal & Maço & 20 & $\mathrm{R} \$ 7,80$ & $\mathrm{R} \$ 156,00$ \\
8 & Lucky Strike Original Azul & Mensal & Maço & 20 & $\mathrm{R} \$ 7,57$ & $\mathrm{R} \$ 151,40$ \\
9 & Dunhill Carlton Effect & Mensal & Maço & 10 & $\mathrm{R} \$ 9,86$ & $\mathrm{R} \$ 98,60$ \\
10 & Rothmans Internacional & Mensal & Maço & 14 & $\mathrm{R} \$ 6,88$ & $\mathrm{R} \$ 96,32$ \\
11 & Malboro Purple & Mensal & Maço & 10 & $\mathrm{R} \$ 9,21$ & $\mathrm{R} \$ 92,10$ \\
12 & Lucky Strike Original Vermelho & Mensal & Maço & 10 & $\mathrm{R} \$ 7,57$ & $\mathrm{R} \$ 75,70$ \\
13 & Rothmans Vermelho & Mensal & Maço & 14 & $\mathrm{R} \$ 5,28$ & $\mathrm{R} \$ 73,89$ \\
14 & Rothmans Int. Double click & Mensal & Maço & 10 & $\mathrm{R} \$ 7,34$ & $\mathrm{R} \$ 73,40$ \\
15 & Kent Derby Azul & Mensal & Maço & 7 & $\mathrm{R} \$ 7,09$ & $\mathrm{R} \$ 49,63$ \\
16 & Kent Derby Prata & Mensal & Maço & 5 & $\mathrm{R} \$ 7,09$ & $\mathrm{R} \$ 35,45$ \\
17 & Malboro Gold & Mensal & Maço & 5 & $\mathrm{R} \$ 6,91$ & $\mathrm{R} \$ 34,55$ \\
18 & Kent Free Vermelho & Mensal & Maço & 4 & $\mathrm{R} \$ 8,49$ & $\mathrm{R} \$ 33,96$ \\
19 & Kent Free Azul & Mensal & Maço & 4 & $\mathrm{R} \$ 8,49$ & $\mathrm{R} \$ 33,96$ \\
20 & Chesterfield Orange & Mensal & Maço & 5 & $\mathrm{R} \$ 4,59$ & $\mathrm{R} \$ 22,95$ \\
21 & Chesterfield Blue & Mensal & Maço & 5 & $\mathrm{R} \$ 4,59$ & $\mathrm{R} \$ 22,95$ \\
\hline
\end{tabular}

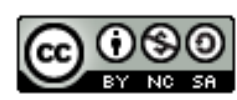


Citação (APA): Nunes, R. P. T. G., Servare, M. W. J., Jr., \& Gomes, T. C. (2022). Implementação de ferramentas da qualidade para gestão de estoque em uma loja de conveniência. Brazilian Journal of Production Engineering, 8(2), 62-78.

Com a ordenação dos itens selecionados, foi possível obter o valor acumulado, que se refere ao custo médio mensal investido com o conjunto estudado, sendo uma capital equivalente a $\mathrm{R} \$ 4.777,32$ gastos mensalmente com a aquisição de cigarros na loja de conveniência. Após encontrar o acumulado, é importante seguir para próxima parte da aplicação da ferramenta, que é calcular a porcentagem de representação de cada item dentro do conjunto de dados e, com isso, descobrir quais itens pertencem a cada classe.

Atualmente, o resultado do percentual e definição da classe de cada itens do conjunto de dados analisado é apresentado na Tabela 3. Conforme especificado anteriormente, produtos da classe A são mais relevantes e requerem maior atenção; produtos da classe B representam um grupo de itens em situação intermediária entre as classes A e C, seu controle pode ser menos rigoroso que os itens de classe $\mathrm{A}$; e, por fim, os produtos da classe $\mathrm{C}$, menos relevantes em termos financeiros, mas que precisam de atenção logo após os produtos das classes A e B.

Tabela 3. Percentual e classificação dos itens

\begin{tabular}{clccc}
\hline $\mathbf{N}^{\mathbf{0}}$ & \multicolumn{1}{c}{ Produto } & \% & \% Acumulado & Classe \\
\hline 1 & Dunhill Carlton & $44,07 \%$ & $44,07 \%$ & $\mathrm{~A}$ \\
\hline 2 & Dunhill Carlton Double Essense & $11,76 \%$ & $55,84 \%$ & $\mathrm{~A}$ \\
\hline 3 & Lucky Strike Double & $7,40 \%$ & $63,24 \%$ & $\mathrm{~A}$ \\
\hline 4 & Rothmans Azul & $6,30 \%$ & $69,53 \%$ & $\mathrm{~A}$ \\
\hline 5 & Malboro Fusion & $5,21 \%$ & $74,74 \%$ & $\mathrm{~A}$ \\
\hline 6 & Lucky Strike Azul & $3,27 \%$ & $78,00 \%$ & $\mathrm{~A}$ \\
\hline 7 & Lucky Strike Verde & $3,27 \%$ & $81,27 \%$ & $\mathrm{~B}$ \\
\hline 8 & Lucky Strike Original Azul & $3,17 \%$ & $84,44 \%$ & $\mathrm{~B}$ \\
\hline 9 & Dunhill Carlton Effect & $2,06 \%$ & $86,50 \%$ & $\mathrm{~B}$ \\
\hline 10 & Rothmans Internacional & $2,02 \%$ & $88,52 \%$ & $\mathrm{~B}$ \\
\hline 11 & Malboro Purple & $1,93 \%$ & $90,45 \%$ & $\mathrm{~B}$ \\
\hline 12 & Lucky Strike Original Vermelho & $1,58 \%$ & $92,03 \%$ & $\mathrm{~B}$ \\
\hline 13 & Rothmans Vermelho & $1,55 \%$ & $93,58 \%$ & $\mathrm{~B}$ \\
\hline 14 & Rothmans Int. Double click & $1,54 \%$ & $95,11 \%$ & $\mathrm{C}$ \\
\hline 15 & Kent Derby Azul & $1,04 \%$ & $96,15 \%$ & $\mathrm{C}$ \\
\hline 16 & Kent Derby Prata & $0,74 \%$ & $96,89 \%$ & $\mathrm{C}$ \\
\hline 17 & Malboro Gold & $0,72 \%$ & $97,62 \%$ & $\mathrm{C}$ \\
\hline 18 & Kent Free Vermelho & $0,71 \%$ & $98,33 \%$ & $\mathrm{C}$ \\
\hline 19 & Kent Free Azul & $0,71 \%$ & $99,04 \%$ & $\mathrm{C}$ \\
\hline 20 & Chesterfield Orange & $0,48 \%$ & $99,52 \%$ & $\mathrm{C}$ \\
\hline 21 & Chesterfield Blue & $0,48 \%$ & $100,00 \%$ & $\mathrm{C}$ \\
\hline & & & \\
\hline
\end{tabular}

Por fim, foi desenvolvido um gráfico para representar a importância de cada classe do conjunto de itens estudados, formando assim, um diagrama de Pareto, conforme Gráfico 1. 
Gráfico 1. Curva ABC para família de produtos cigarros
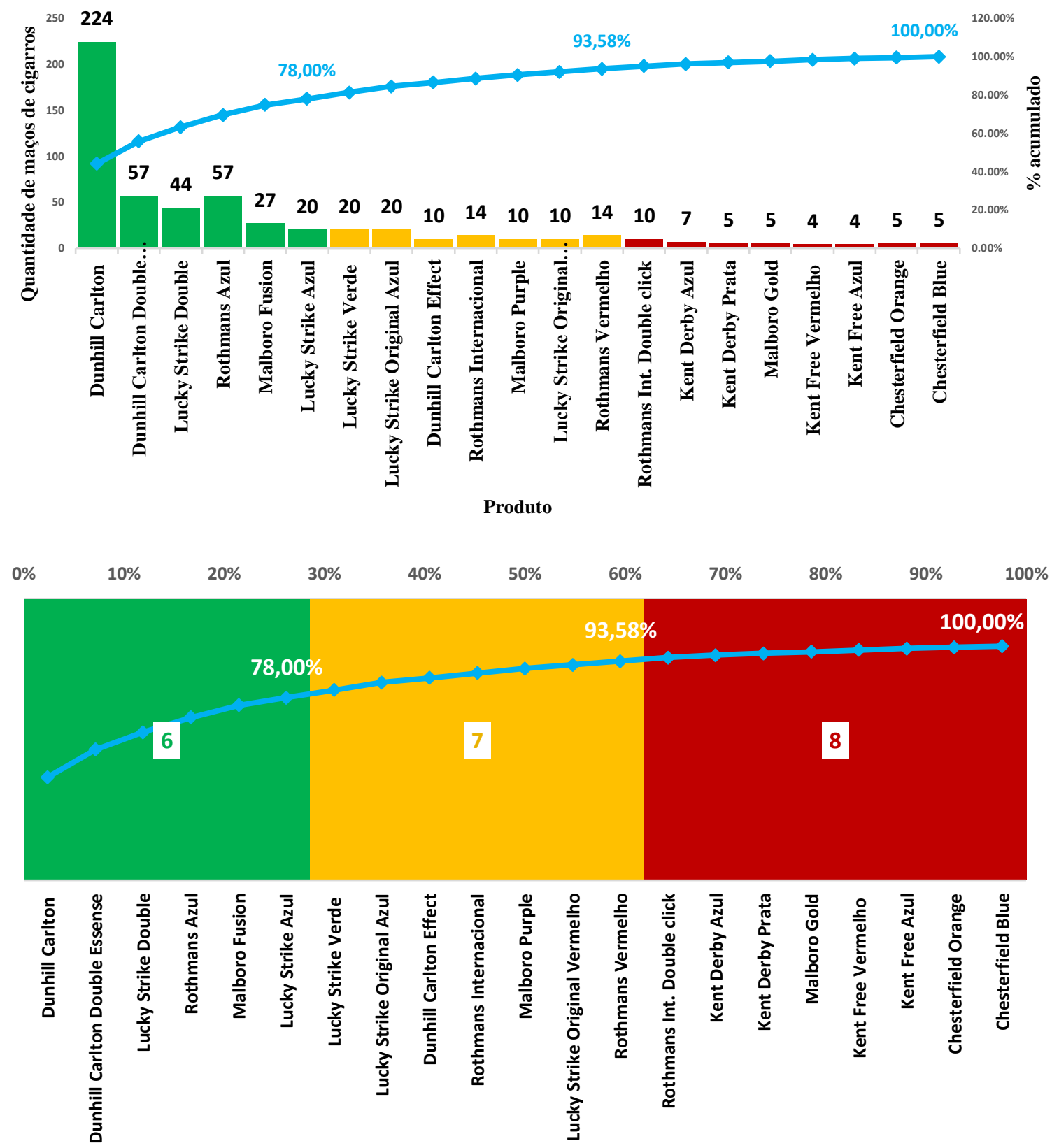

Após levantamento dos dados e a aplicação de todas as etapas da Curva ABC, é possível ter uma visão mais clara e assertiva da importância de cada item e sua determinada classificação dentro do conjunto de produtos. A Curva ABC é uma ferramenta muito importante no auxílio ao controle dos estoques, pois ela proporciona diversos benefícios, sendo alguns deles:

- $\quad$ Estoques mais bem sincronizados com a demanda local;

- Mais oportunidades de negociação com fornecedores;

- $\quad$ Otimização da logística;

- $\quad$ Melhor aplicação do capital para compras;

- $\quad$ E gestão da vida útil dos produtos.

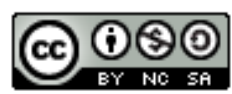


Citação (APA): Nunes, R. P. T. G., Servare, M. W. J., Jr., \& Gomes, T. C. (2022). Implementação de ferramentas da qualidade para gestão de estoque em uma loja de conveniência. Brazilian Journal of Production Engineering, 8(2), 62-78.

A organização dos cigarros dispostos no estoque, conforme prioridade dos itens do conjunto de dados estudados na loja de conveniência foi realizado como disposto na Figura 7.

Figura 7. Organização dos cigarros conforme Curva ABC, após aplicação do 5S

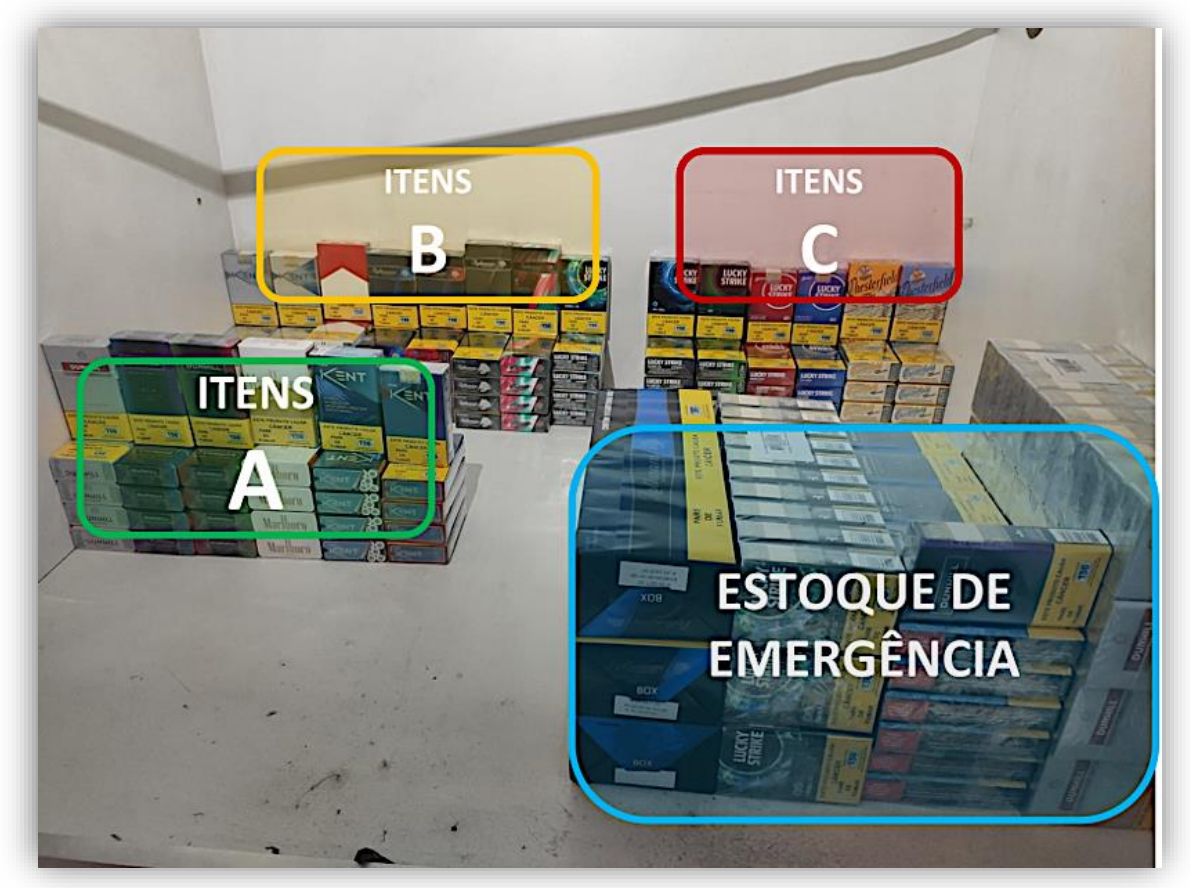

\subsection{Planos de Melhoria (5W2H)}

Após aplicação do diagrama de Ishikawa, programa 5S e curva $\mathrm{ABC}$ foi possível compreender os problemas e causas do setor analisado. Na presente etapa, torna-se viável a elaboração de um plano com propostas de melhoria, com intuito de auxiliar no controle do estoque da empresa estudada, como também na sua organização de forma geral. Para isso, fez-se uso da ferramenta 5W2H composta por uma tabela de sete colunas contendo perguntas que representam cada categoria, conforme detalhamento do Quadro 1.

Quadro 1.5W2H para gestão do estoque

\begin{tabular}{|c|c|c|c|c|c|c|}
\hline $\begin{array}{l}\text { What? } \\
\text { (O que?) }\end{array}$ & $\begin{array}{c}\text { Why? } \\
\text { (Por quê?) }\end{array}$ & $\begin{array}{c}\text { When? } \\
\text { (Quando?) }\end{array}$ & $\begin{array}{c}\text { Who? } \\
\text { (Quem?) }\end{array}$ & $\begin{array}{l}\text { Where? } \\
\text { (Onde?) }\end{array}$ & $\begin{array}{c}\text { How? } \\
\text { (Como?) }\end{array}$ & $\begin{array}{c}\text { How } \\
\text { much? } \\
\text { (Quanto?) } \\
\end{array}$ \\
\hline $\begin{array}{l}\text { Planilha de } \\
\text { Controle de } \\
\text { Estoque e } \\
\text { Fornecedores }\end{array}$ & $\begin{array}{c}\text { Para controlar } \\
\text { estoque, e assim, } \\
\text { solicitar as compras } \\
\text { antes de faltar e na } \\
\text { quantidade } \\
\text { adequada. }\end{array}$ & $15 / 12 / 2021$ & $\begin{array}{l}\text { Toda } \\
\text { equipe }\end{array}$ & $\begin{array}{c}\text { Loja de } \\
\text { Conveniência }\end{array}$ & $\begin{array}{l}\text { Com a } \\
\text { ferramenta } \\
\text { Microsoft } \\
\text { Excel. }\end{array}$ & - \\
\hline $\begin{array}{c}\text { Plano de } \\
\text { Limpeza e } \\
\text { Organização } \\
\text { do Estoque }\end{array}$ & $\begin{array}{l}\text { Para manter local } \\
\text { limpo, organizado e } \\
\text { padronizado. }\end{array}$ & $20 / 11 / 2021$ & $\begin{array}{c}\text { Toda } \\
\text { equipe }\end{array}$ & Almoxarifado & $\begin{array}{c}\text { Com } \\
\text { materiais de } \\
\text { limpeza e } \\
\text { etiqueta de } \\
\text { identificação. }\end{array}$ & - \\
\hline $\begin{array}{l}\text { Treinamento } \\
\text { sobre } \\
\text { Controle de } \\
\text { Estoque e 5S }\end{array}$ & $\begin{array}{c}\text { Para ter } \\
\text { conhecimento sobre } \\
\text { o assunto. }\end{array}$ & $20 / 12 / 2021$ & $\begin{array}{l}\text { Toda } \\
\text { equipe }\end{array}$ & $\begin{array}{c}\text { Loja de } \\
\text { Conveniência }\end{array}$ & $\begin{array}{l}\text { Canais do } \\
\text { YouTube. }\end{array}$ & - \\
\hline
\end{tabular}

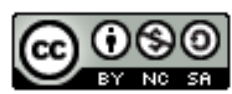


As propostas são simples e podem ser feitas por todos os colaboradores da loja de conveniência. Com relação ao custo, que se encontra na última coluna do Quadro 4, é possível visualizar que não foram colocados gastos para estes planos, visto que, como já foi dito, pode ser aplicado por qualquer indivíduo da loja, por ser uma empresa familiar. No entanto, é possível comprar a planilha de controle e cursos presenciais e/ou online para os treinamentos, porém, vale ressaltar que é possível ter gastos mínimos para as propostas da ferramenta apresentada.

\section{CONSIDERAÇÕES FINAIS}

Por meio deste estudo, tornou-se possível a aplicação de ferramentas como curva $\mathrm{ABC}$, diagrama de Ishikawa, 5S e 5W2H em uma loja de conveniência. Os resultados mostraram melhor controle do estoque, organização, padronização e limpeza não apenas do almoxarifado, foco deste artigo, mas também da loja com um todo. Vale ressaltar que a empresa estudada ainda é nova e está se adaptando ao mercado e buscando melhorar continuamente. Para que isso ocorra, as ferramentas aplicadas no presente trabalho mostraram-se de grande importância.

O presente trabalho buscou entender o processo logístico de entrada e saídas de mercadorias, restrito neste artigo a família de produtos dos tabacos e, após tal compreensão, desenvolveu-se um plano para otimizar o fluxo e controle do estoque de cigarros utilizando ferramentas da qualidade, visando melhor controle, organização e gerenciamento dos itens armazenados, para assim atender cada vez melhor a demanda local.

Ademais, é cabível afirmar que as pessoas são a chave para transformação de qualquer cenário, e que as ferramentas e controles só funcionarão com disciplina e empenho daqueles que fazem parte da empresa. Assim, os resultados positivos tornam-se apenas consequência de um trabalho consistente.

Como propostas de trabalhos futuros, sugere-se um estudo mais aprofundado sobre a previsão de demanda, para que seja possível aperfeiçoar ainda mais com essa metodologia o gerenciamento logístico da loja de conveniência estudada. Assim, alicerçando não apenas um melhor monitoramento, organização, padronização e limpeza da loja com um todo, mas também uma previsão mais apurada e assertiva de demanda local, possibilitando melhor aproveitamento do capital da empresa proposta mencionada no decorrer deste artigo.

\section{REFERÊNCIAS}

Ajala, R. S. \& Giordani, R., de. (2018). Proposta de gestão de estoques para atacado: um estudo de caso. Revista Latino-Americana de Inovação e Engenharia de Produção - RELAINEP, 6(9), 40-60. http://dx.doi.org/10.5380/relainep.v6i9

Arnold, J. R. T. (1999). Administração de materiais: uma introdução. Atlas.

Cabral, A. C. S., Zeitouni, M. M. S., \& Souza, M. A. de. (2017). Análise da aplicação de ferramentas básicas da qualidade em uma empresa distribuidora de medicamentos. In: XXXVII Encontro Nacional De Engenharia De Produção - ABEPRO, 37, Joinville, SC. Anais. Recuperado de http://www.abepro.org.br/biblioteca/TN_STO_239_389_33090.pdf

Campos, V. F. (2004). Controle da Qualidade Total no estilo japonês. $8^{\mathrm{a}}$ edição. INDG Tecnologia e Serviço, Nova Lima, MG, Brasil.

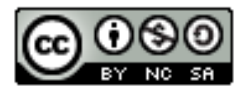


Citação (APA): Nunes, R. P. T. G., Servare, M. W. J., Jr., \& Gomes, T. C. (2022). Implementação de ferramentas da qualidade para gestão de estoque em uma loja de conveniência. Brazilian Journal of Production Engineering, 8(2), 62-78.

Carvalho, A. R (2017). Método Monte Carlo e suas aplicações. Mestrado Profissional em Matemática em Rede Nacional, Boa Vista, RR. PROFMAT: 2017. Recuperado de http://repositorio.ufrr.br:8080/jspui/bitstream/prefix/388/1/M\%C3\%A9todo\%20Monte\%20Ca rlo\%20e\%20suas\%20aplica\%C3\%A7\%C3\%B5es...\%20Carvalho.pdf

Carvalho, M. \& Paladini, E. (2013). Gestão da qualidade: teoria e casos. Elsevier Brasil.

Fernandes, F. C. F. \& Godinho, M., Filho. (2010). Planejamento e controle da produção: dos fundamentos ao essencial. São Paulo: Atlas, 2010.

Freitas, R. P. (2008). Controle de Estoque de Peças de Reposição: Revisão da Literatura e um Estudo de Caso. Dissertação de Mestrado, Pontifícia Universidade Católica do Rio de Janeiro, Departamento de Engenharia Industrial, Rio de Janeiro. Recuperado de https://www.maxwell.vrac.puc-rio.br/12396/12396_1.PDF

Giacomin, C., Gomes, T. C., \& Servare Junior, M. W. J. (2021). Controle de estoques como diferencial estratégico: uma análise bibliométrica por meio do PROKNOW-C. Brazilian Journal of Production Engineering-BJPE, 41-55.

Gomes, A. C. N., Ferreira, A. R. D. S. V., Borges, F. H., \& da Silva, E. B. (2018). A aplicação das ferramentas da qualidade na criação de Procedimentos Operacionais Padronizados em dois restaurantes de meios de hospedagem no Rio de Janeiro. Exacta, 16(2), 95-106. https://doi.org/10.5585/exactaep.v16n2.7066

Guerra, O. \& Teixeira F. (2010). A sobrevivência das pequenas empresas no desenvolvimento capitalista. Revista de Economia Política,30(1), 124-139. https://doi.org/10.1590/S0101$\underline{31572010000100008}$

Ishikawa, K. (1986). TQC-Total Quality Control: estratégia e administração da qualidade. IMC Internacional Sistemas Educativos.

Lins, B. F. (1993). Ferramentas básicas da qualidade. Ciência da Informação, 22(2), 153-161. https://doi.org/10.18225/ci.inf..v22i2.502

Lucas, G. A., Ferreira, L. G. M., Ribeiro, A., \& Gontijo, F. B. de. (2018). Gestão de estoque: eficácia do uso das ferramentas 5s e diagrama de Ishikawa. In: XXXVIII Encontro Nacional De Engenharia De Produção - ABEPRO, 38, Maceió, AL. Anais. Recuperado de http://www.abepro.org.br/biblioteca/TN_STO_259_488_36357.pdf

Piran, A., Azzolini, J. C., \& Vanin, A. B. (2020). Proposta para melhoria na gestão de estoque em uma empresa que atua no setor de distribuição de alimentos do meio oeste catarinense. In: XL Encontro Nacional De Engenharia De Produção - ABEPRO, 40, Plataforma Online. Anais. Recuperado de http://www.abepro.org.br/biblioteca/TN STO 351 1804 41175.pdf

Possale, S. \& Callefi, J. S. (2020). Implementação e continuidade do Ciclo PDCA: Um estudo de caso no setor metal mecânico. Gepros: Gestão da Produção, Operações e Sistemas, 15(3), 155 .

Rebello, M. A. D. F. R. (2005). Implantação do Programa 5S para a conquista de um ambiente de qualidade na biblioteca do Hospital Universitário da Universidade de São Paulo. RDBCI: Revista Digital de Biblioteconomia e Ciência da Informação, 3(2), 165-182.

Reis, M. F., Litter, B. S. S., Santos, M., Lima, A. R., \& Paixão, A. C., de. (2019). Proposta de melhorias no controle de estoque utilizando a ferramenta masp em uma fábrica de descartáveis. In: XXXIX Encontro Nacional De Engenharia De Produção - ABEPRO, 39, 2019, Santos, SP. Anais. Recuperado de http://www.abepro.org.br/biblioteca/TN STO 293 1659 36874.pdf 

de estoque em uma loja de conveniência. Brazilian Journal of Production Engineering, 8(2), 62-78.

Santos, B. T. \& Lubiana, C. (2017). O uso da curva ABC para a tomada de decisão na composição de estoque. Inter-American Journal of Development and Research, 1(1), 62-78.

Silva, F. H. L., Oliveira, M. M., Lima, R. A. A., Rodrigues, L. M. S., \& Assis, L. F. de. (2016). Estudo sobre métodos de previsão de demanda em uma indústria de laticínios da cidade de Sousa - PB. In: XXXVI Encontro Nacional De Engenharia De Produção - ABEPRO, 36, 2016, João Pessoa, PB. Anais. Recuperado http://www.abepro.org.br/biblioteca/TN_STP_226_319_30207.pdf

Silva, J. M. D. (1996). O ambiente da qualidade na prática-5S. Belo Horizonte: Fundação Christiano Ottoni, 26.

Sinpospetro Campinas. (2018). Lojas de Conveniência: Setor fatura $R \$ 7,2$ bilhões por ano. Recuperado de http://www.sinpospetrocampinas.com.br/lojas-de-conveniencia-setor-fatura-r72-bilhoes-por-ano/

Slack, N.; Chambers, S.; Johnston, R. (2009). Administração da produção. São Paulo: Atlas.

Trainotti, M. (2007). Aplicação da Metodologia 5S, visando a Melhoria do Processo Organizacional em uma Fundação de Direito Privado: um estudo de caso. $119 \mathrm{f}$. Dissertação (Mestrado em Engenharia).

Werkema, M. C. C. (1995). As ferramentas da qualidade no gerenciamento de processos 1. ed. Belo Horizonte: Sografe. 